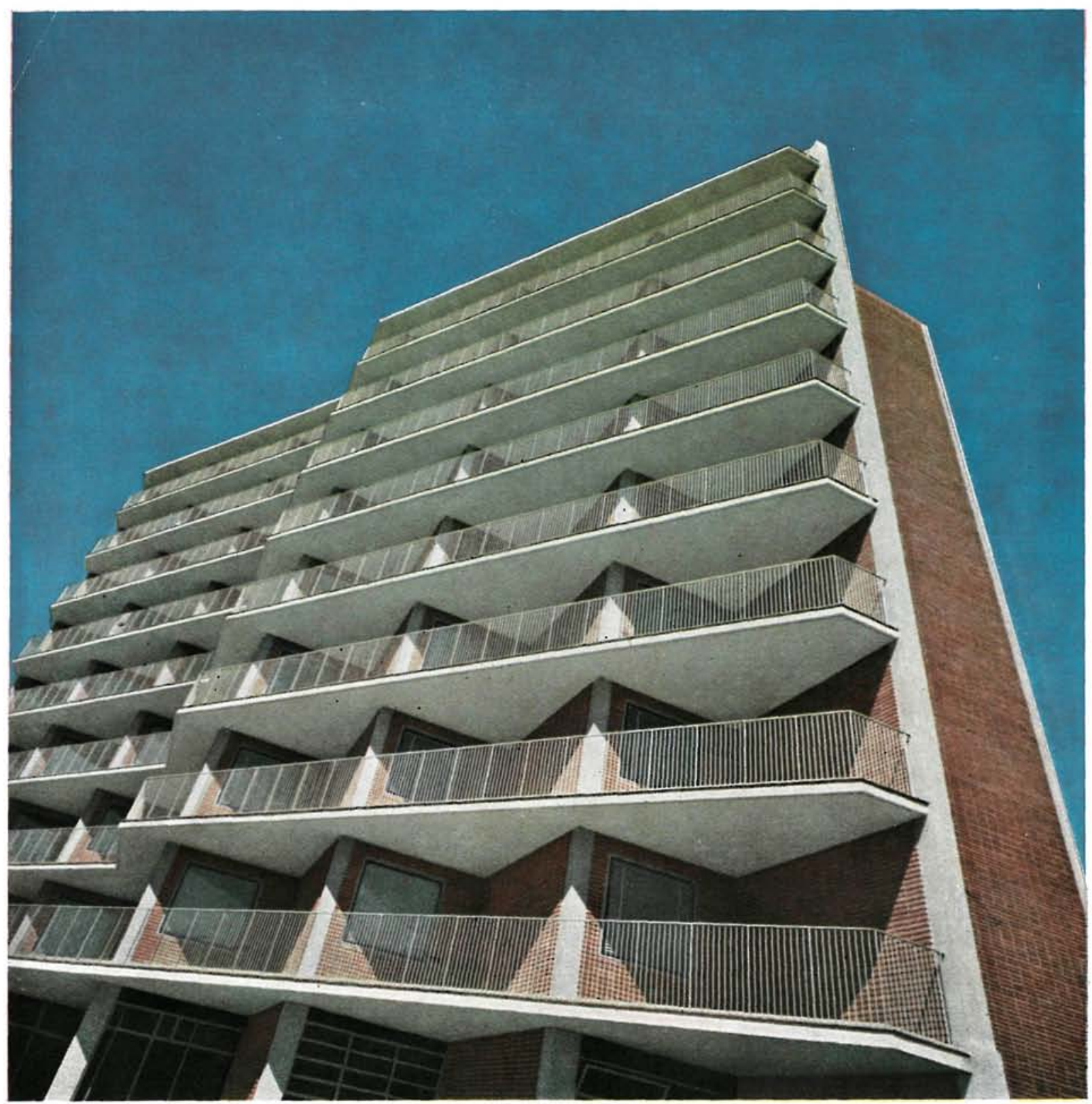

$142 \cdot 13$

\title{
colegio mayor Aquinas
}

JOSE M. ${ }^{a}$ GARCIA DE PAREDES y RAFAEL DE LA HOZ

arquitectos 


\section{colegio mayor aquinas}
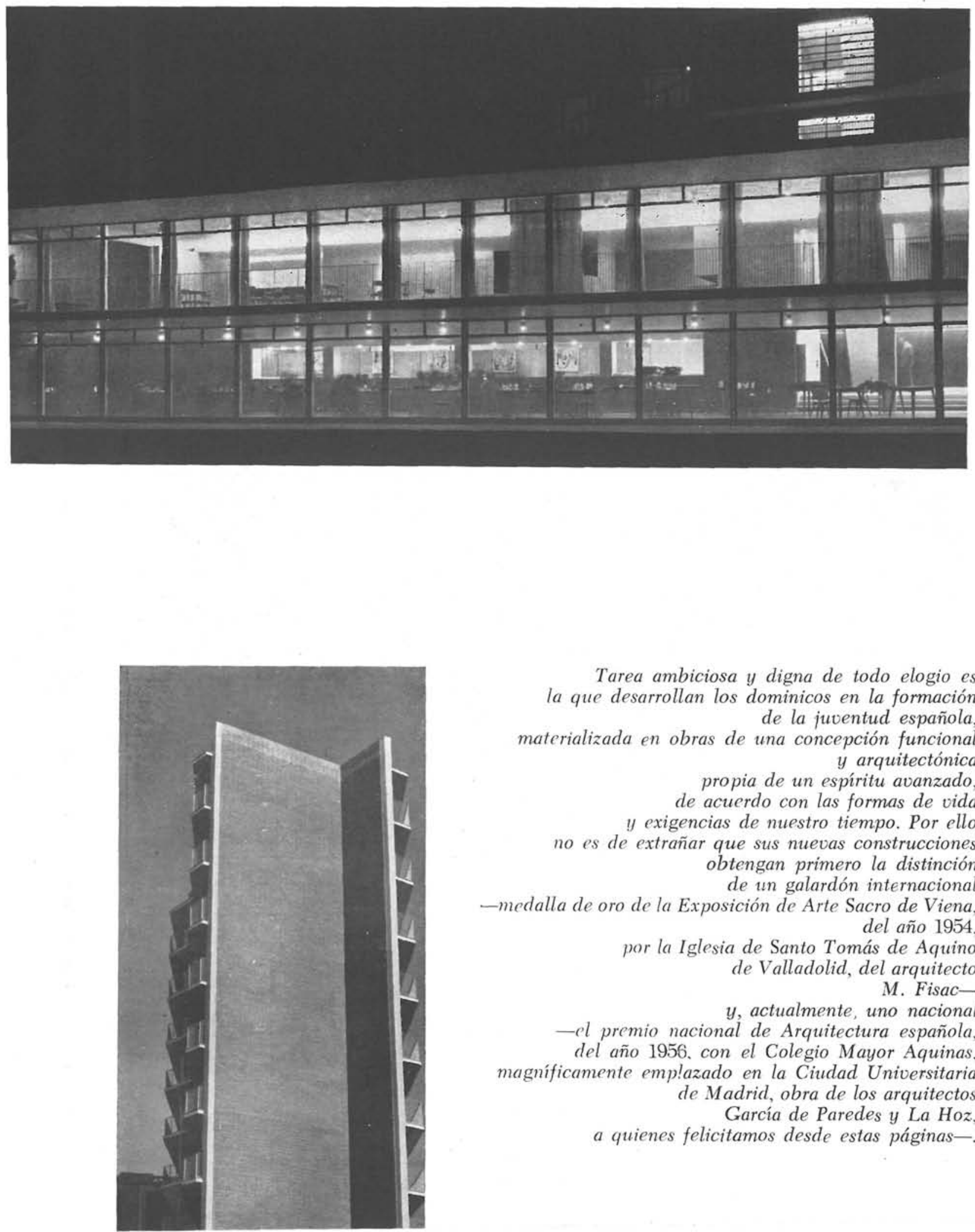

Tarea ambiciosa y digna de todo elogio es la que desarrollan los dominicos en la formación de la juventud española, materializada en obras de una concepción funcional $y$ arquitectónica propia de un espíritu avanzado,

de acuerdo con las formas de vida $y$ exigencias de nuestro tiempo. Por ello no es de extrañar que sus nuevas construcciones obtengan primero la distinción de un galardón internacional - medalla de oro de la Exposición de Arte Sacro de Viena, del año 1954 por la Iglesia de Santo Tomás de Aquino de Valladolid, del arquitecto M. Fisac$y$, actualmente, uno nacional - el premio nacional de Arquitectura española, del año 1956. con el Colegio Mayor Aquinas. magníficamente emp!azado en la Ciudad Universitaria de Madrid, obra de los arquitectos

García de Paredes y $\mathrm{La} \mathrm{Hoz}$, a quienes felicitamos desde estas páginas-. 

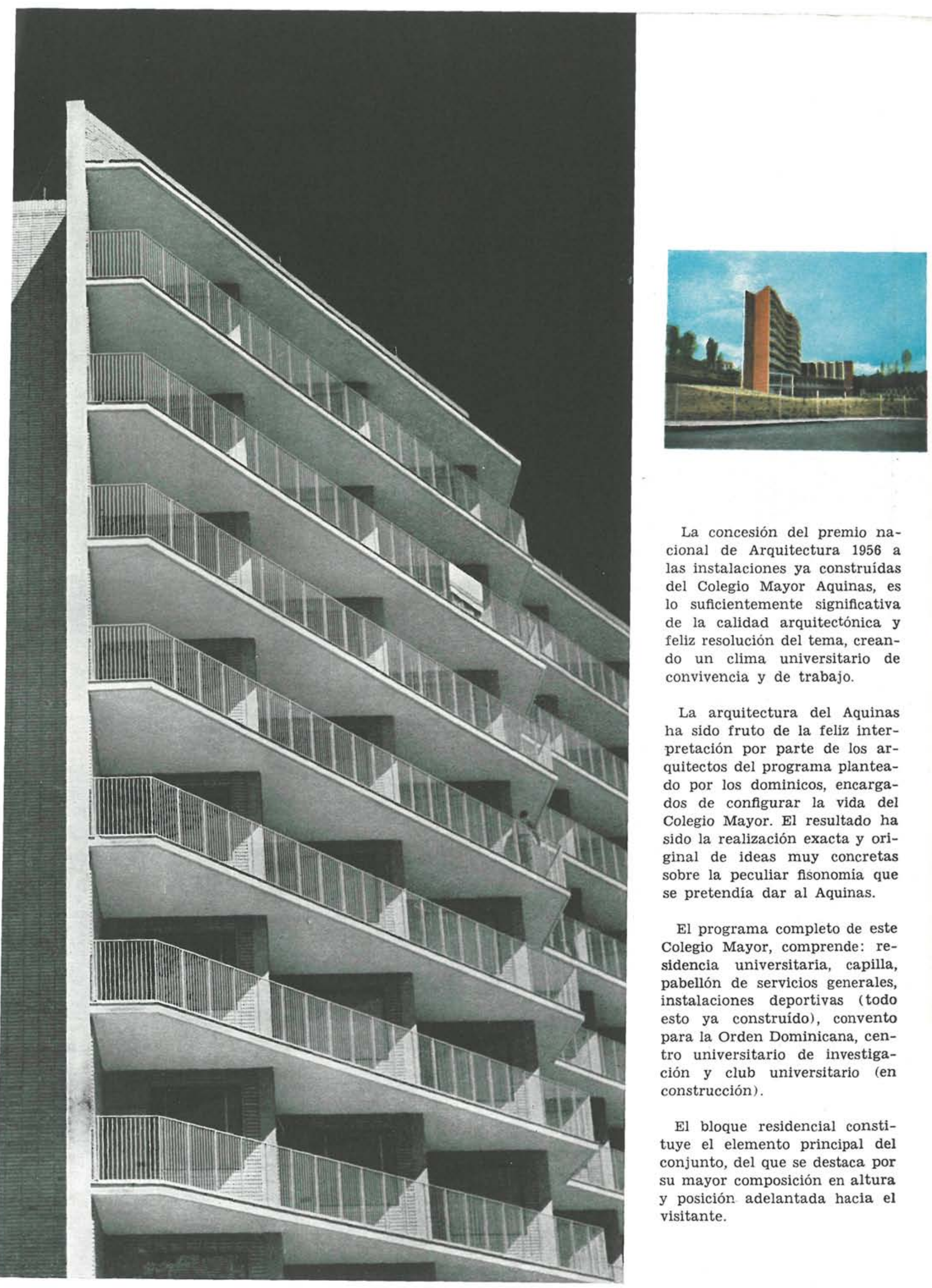

La concesión del premio nacional de Arquitectura 1956 a las instalaciones ya construídas del Colegio Mayor Aquinas, es lo suficientemente significativa de la calidad arquitectónica y feliz resolución del tema, creando un clima universitario de convivencia y de trabajo.

La arquitectura del Aquinas ha sido fruto de la feliz interpretación por parte de los arquitectos del programa planteado por los dominicos, encargados de configurar la vida del Colegio Mayor. El resultado ha sido la realización exacta y original de ideas muy concretas sobre la peculiar fisonomia que se pretendía dar al Aquinas.

El programa completo de este Colegio Mayor, comprende: residencia universitaria, capilla, pabellón de servicios generales, instalaciones deportivas (todo esto ya construído), convento para la Orden Dominicana, centro universitario de investigación y club universitario (en construcción).

El bloque residencial constituye el elemento principal del conjunto, del que se destaca por su mayor composición en altura y posición adelantada hacia el visitante. 


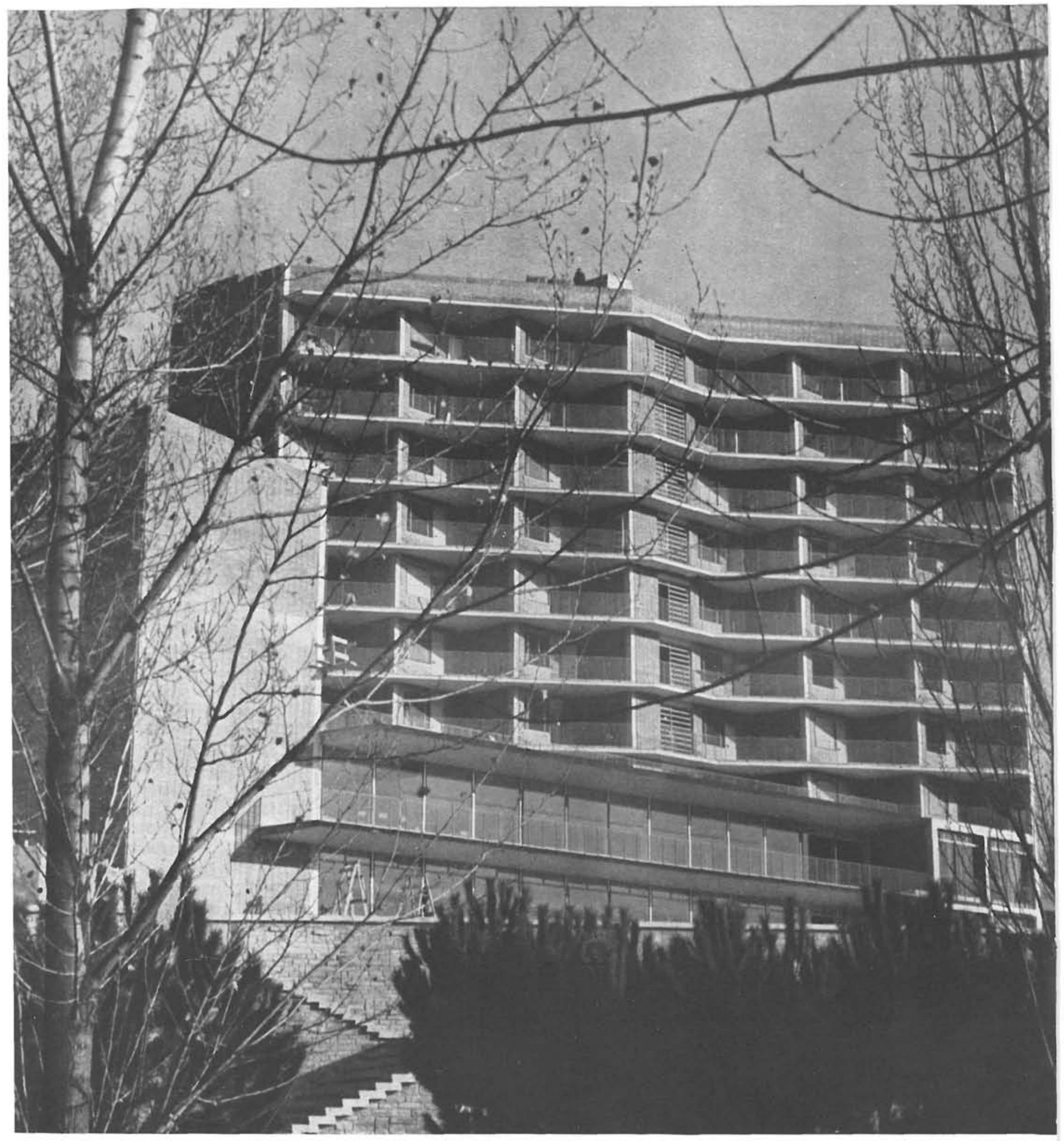

Dos objetivos fundamentales presidieron la redacción de su proyecto: el primero pretendia la creación de espacios diáfanos, capaces de ambientar el espiritu de convivencia y apertura, que debe caracterizar la vida del Colegio Mayor, como colectividad que nunca debe llegar a sentirse masa enclaustrada. El segundo consistía en conseguir de la Arquitectura una colaboración eficaz para la creación de un espiritu de disciplina y de trabajo, conforme las características propias de la mentalidad y exigencias del universitario, es decir, sin que rigideces reglamentarias agobien el desarrollo de su vida ordinaria, ya que el Colegio Mayor no tiene por qué perder cierto sentido de familia y de hogar 

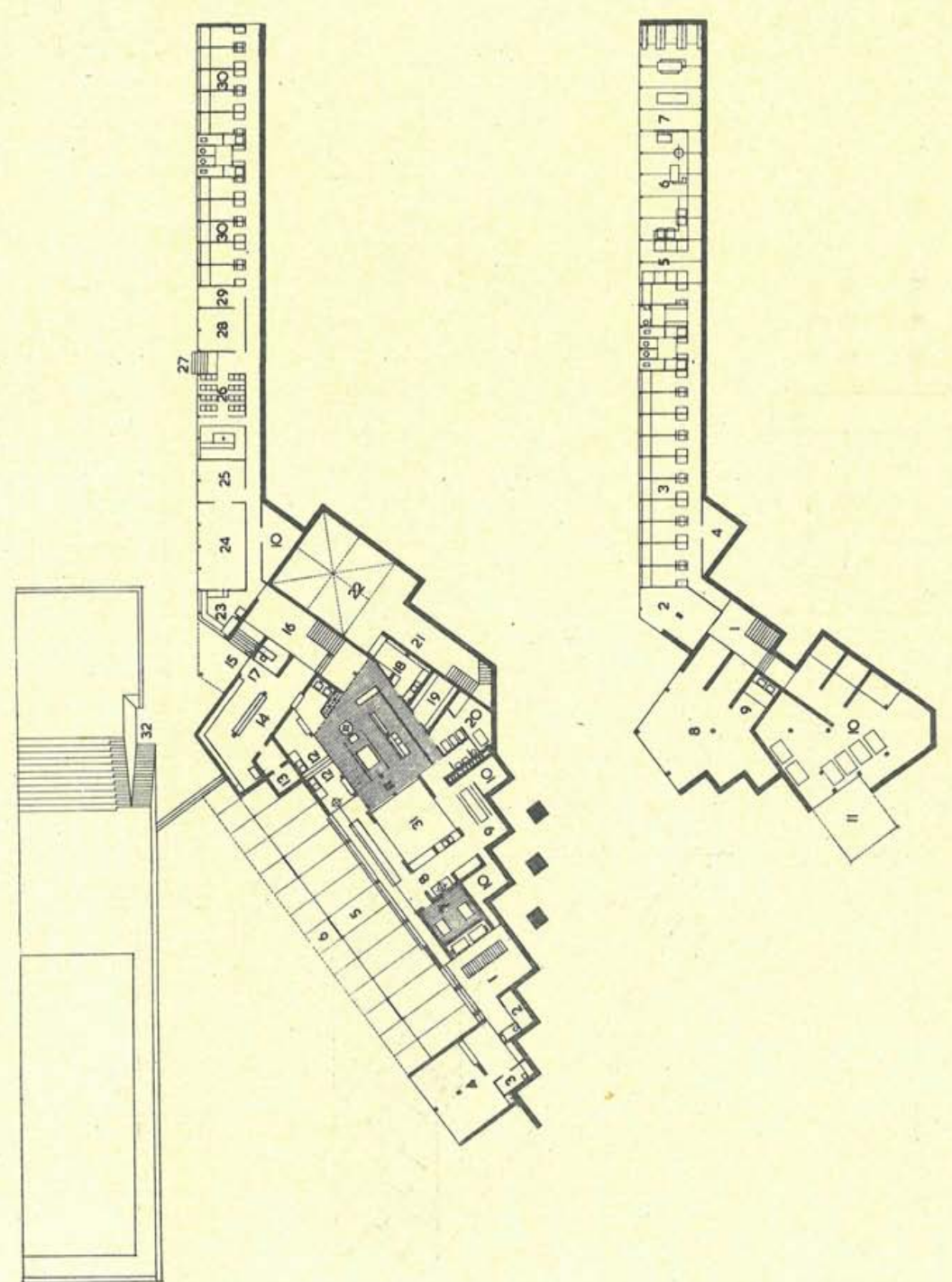

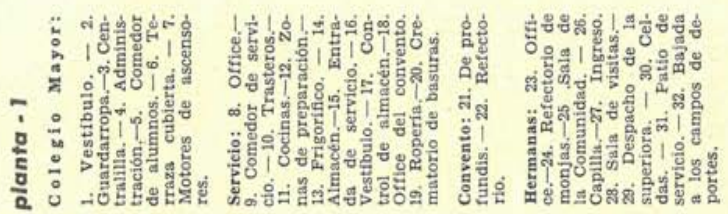
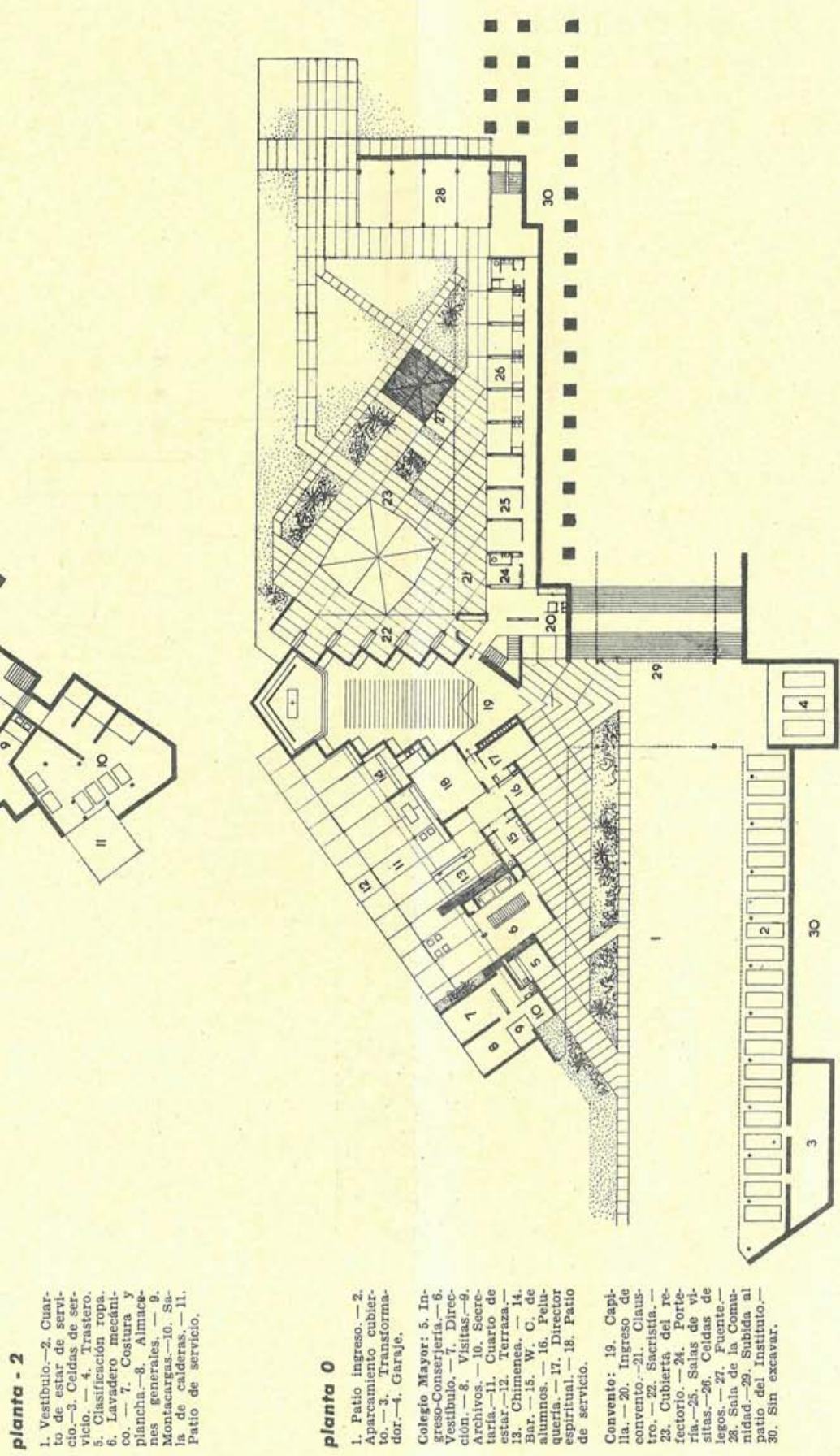

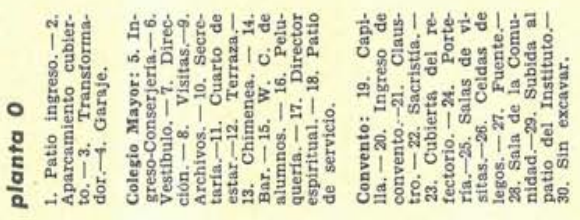




\section{plantas}

ò d

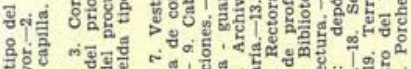

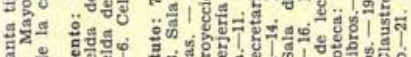

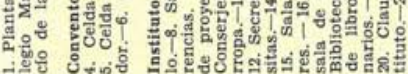

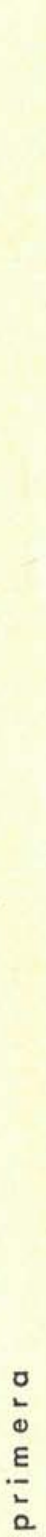

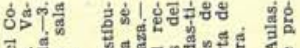

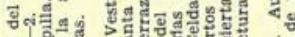

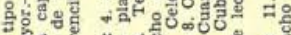

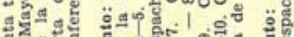
웜

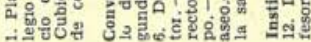

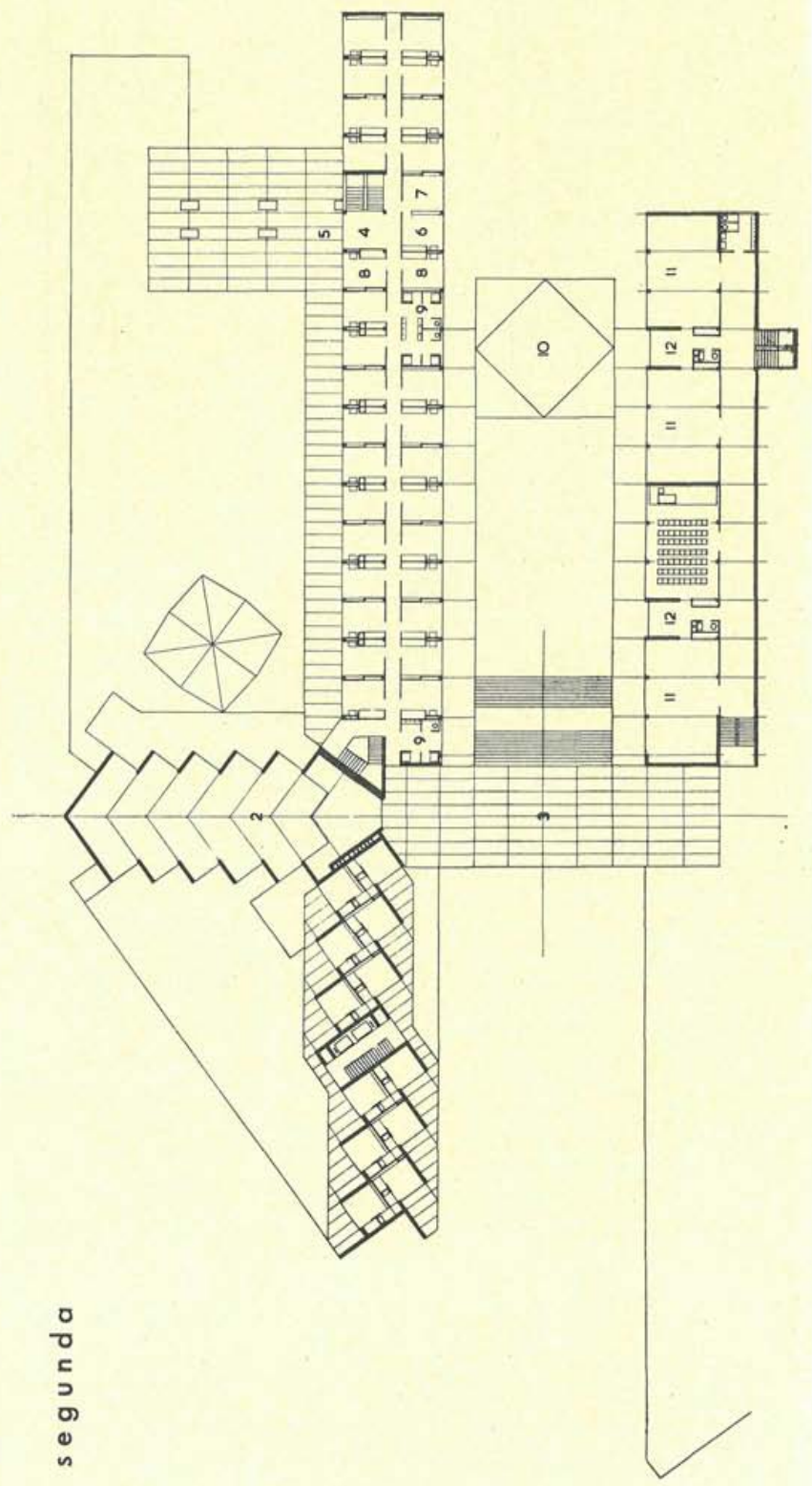




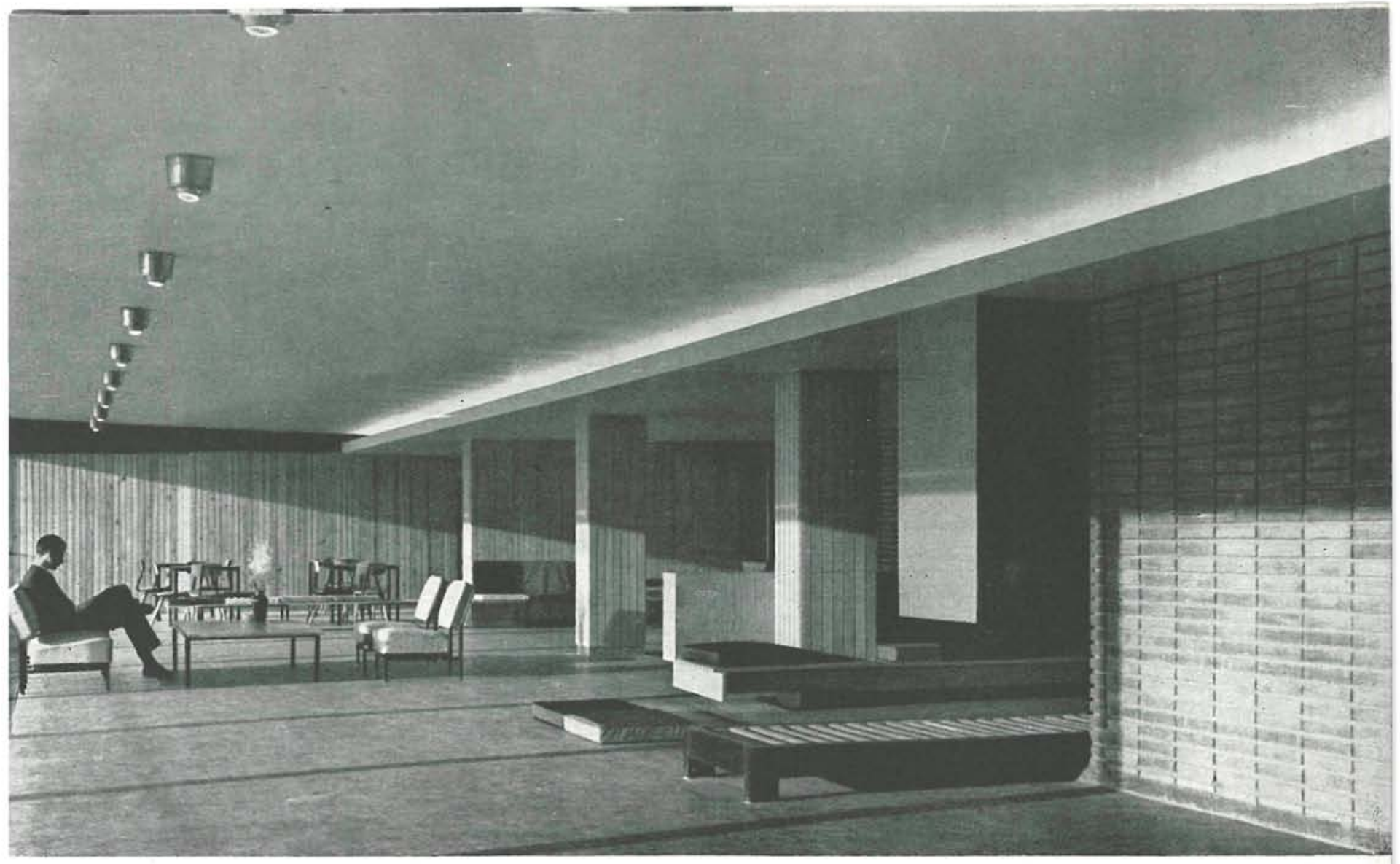

A la realización del primer propósito se destinan las dos primeras plantas del edificio. En la planta de acceso, el pretexto de un "hall" de entrada introduce sin solución de continuidad en el lugar de convivencia general-distribuído en una perfecta continuidad de espacio-, capaz de acoger pequeños grupos en torno al fuego, a una mesa de revistas, a la radio... En uno de sus ángulos, al fondo, se sitúa el pequeño bar, y con posibilidades de fácil y total aislamiento, un lugar reservado para las audiciones musicales. Todas estas dependencias están totalmente abiertas, a poniente, a través de un cerramiento acristalado, con vistas dominantes sobre la Casa de Campo y Sierra del Guadarrama. La planta inferior está destinada al comedor; en uno de sus lados, un mostrador corrido permite un cómodo y rápido sistema de autoservicio; las mesas, distribuídas en el espacio central, hacen posible la reunión en pequeños grupos, con máxima libertad de movimiento, quedando el otro lado, como la planta superior, totalmente abierto hacia el horizonte.
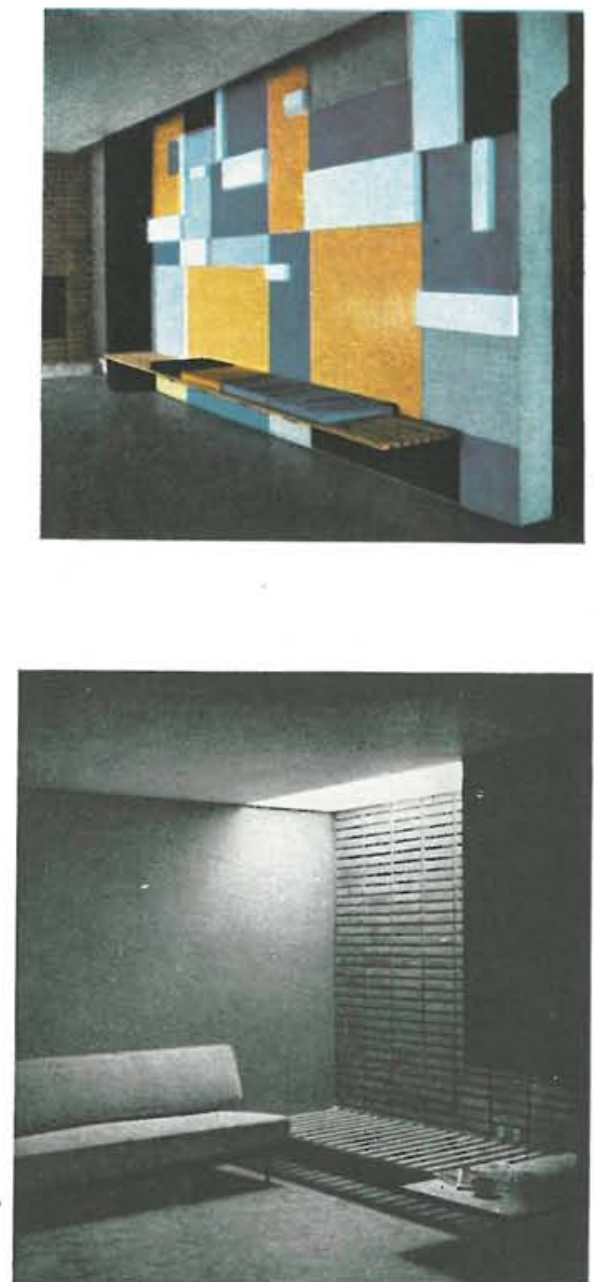


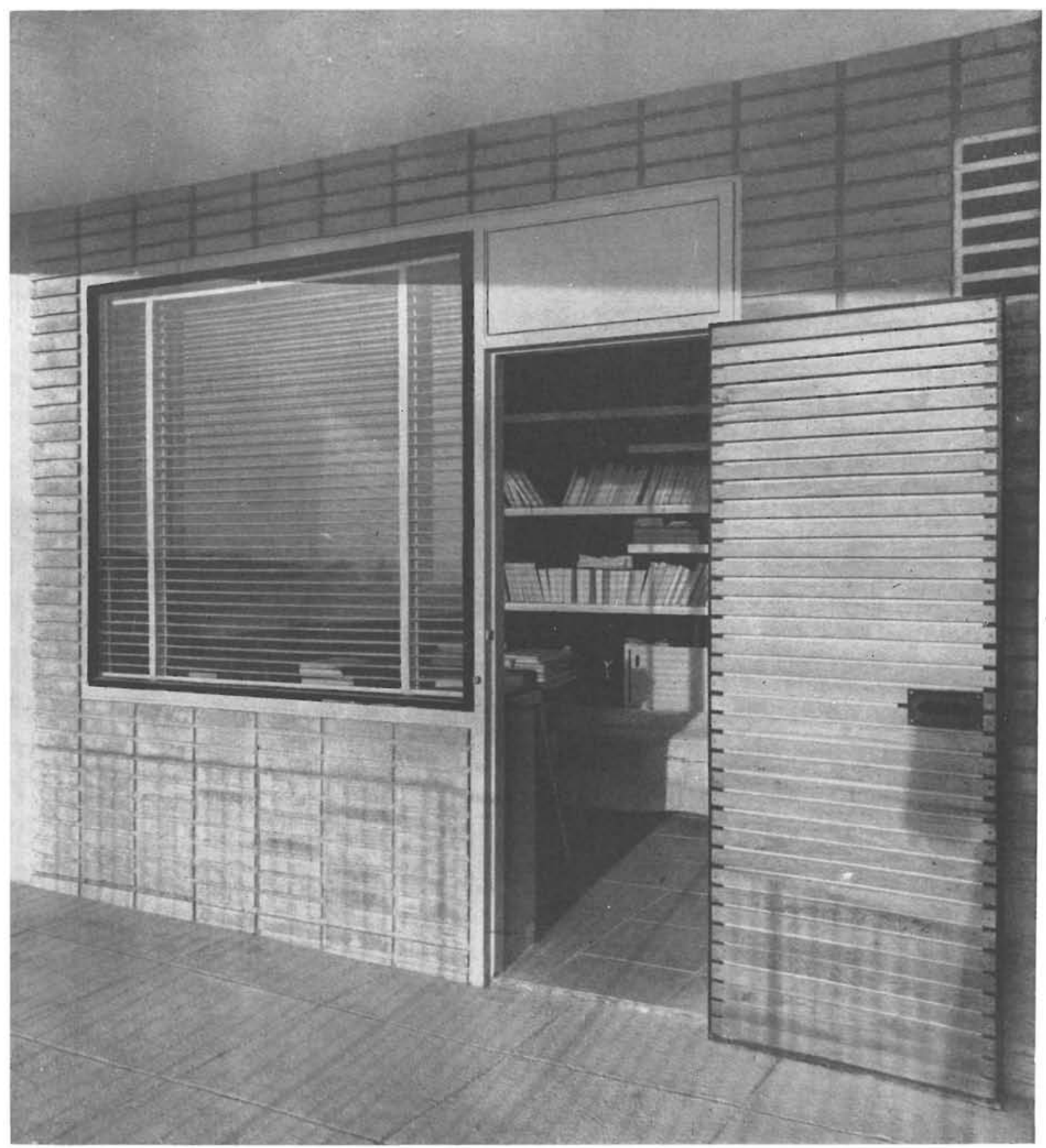

El eje del edificio coincide con el heliotérmico, plegándose las fachadas sobre sí mismas para orientar sus planos parciales hacia el punto de máxima influencia de luz.

La única escalera central se abre directamente a los balcones corridos de ambas fachadas, que constituyen la solución actual del clásico corredor de las casas de vecindad madrileñas.

El sucesivo juego de planos de las fachadas, resuelto en ángulo recto, permite la distribución de la puerta de acceso a la habitación y de un gran ventanal-junto a la zona de trabajo-en uno de sus planos, mientras que el otro es totalmente ciego, dándole a la habitación su individual independencia.

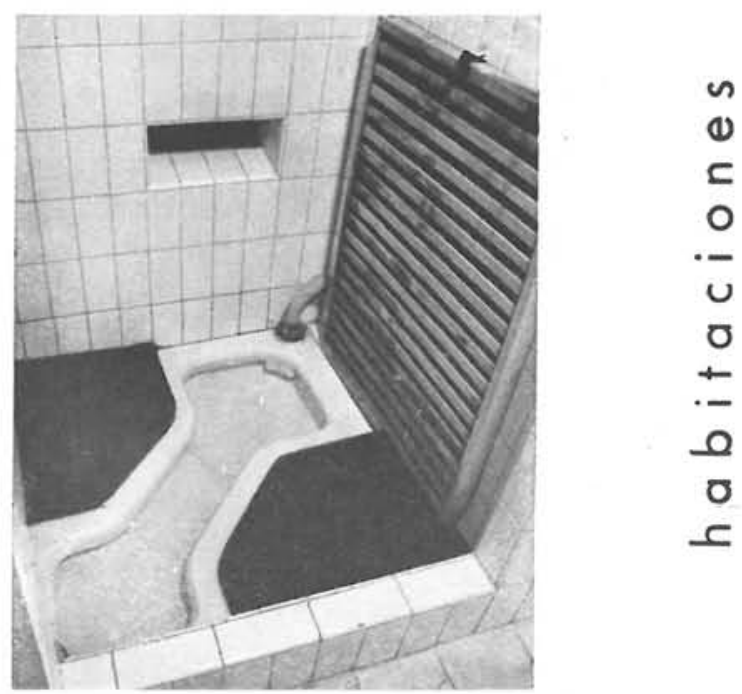



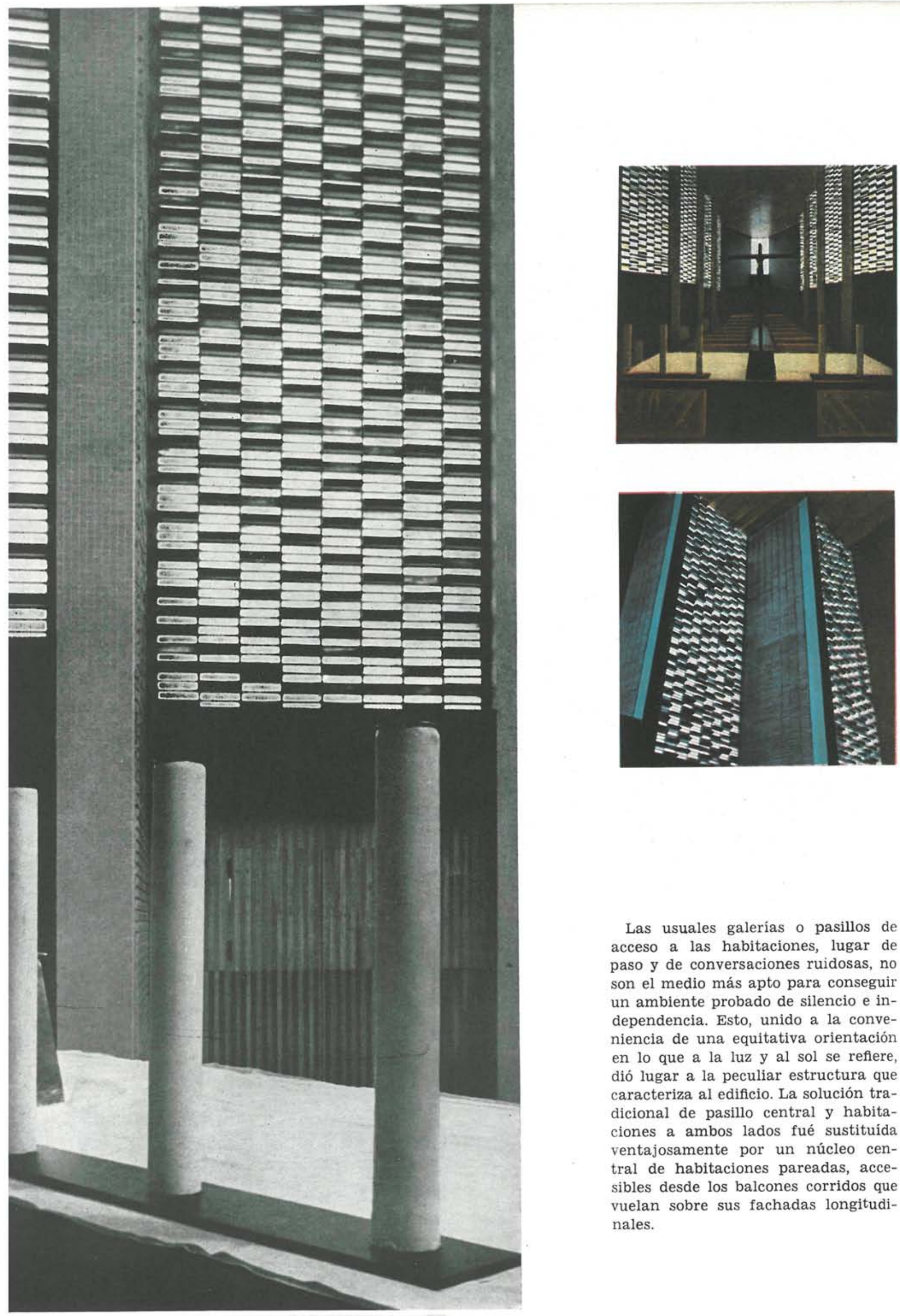

Las usuales galerias o pasillos de acceso a las habitaciones, lugar de paso y de conversaciones ruidosas, no son el medio más apto para conseguir un ambiente probado de silencio e independencia. Esto, unido a la conveniencia de una equitativa orientación en lo que a la luz y al sol se refiere, dió lugar a la peculiar estructura que caracteriza al edificio. La solución tradicional de pasillo central y habitaciones a ambos lados fué sustituída ventajosamente por un núcleo central de habitaciones pareadas, accesibles desde los balcones corridos que vuelan sobre sus fachadas longitudinales. 


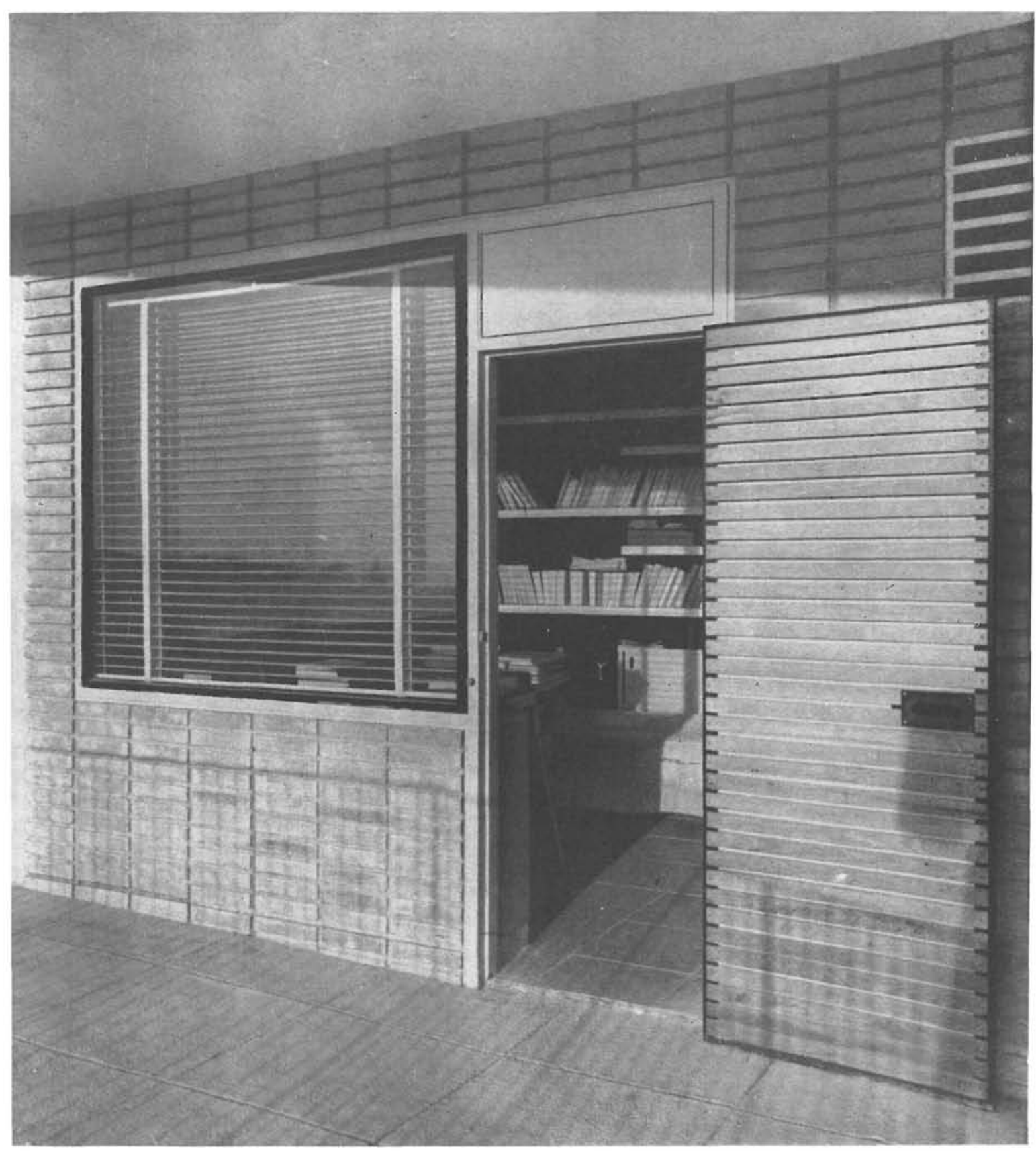

Fotos: M GARCIA MOYA, J. CALVO Y BALMES

El eje del edificio coincide con el heliotérmico, plegándose las fachadas sobre sí mismas para orientar sus planos parciales hacia el punto de máxima influencia de luz.

La única escalera central se abre directamente a los balcones corridos de ambas fachadas, que constituyen la solución actual del clásico corredor de las casas de vecindad madrileñas.

El sucesivo juego de planos de las fachadas, resuelto en ángulo recto, permite la distribución de la puerta de acceso a la habitación y de un gran ventanal-junto a la zona de trabajo-en uno de sus planos, mientras que el otro es totalmente ciego, dándole a la habitación su individual independencia.

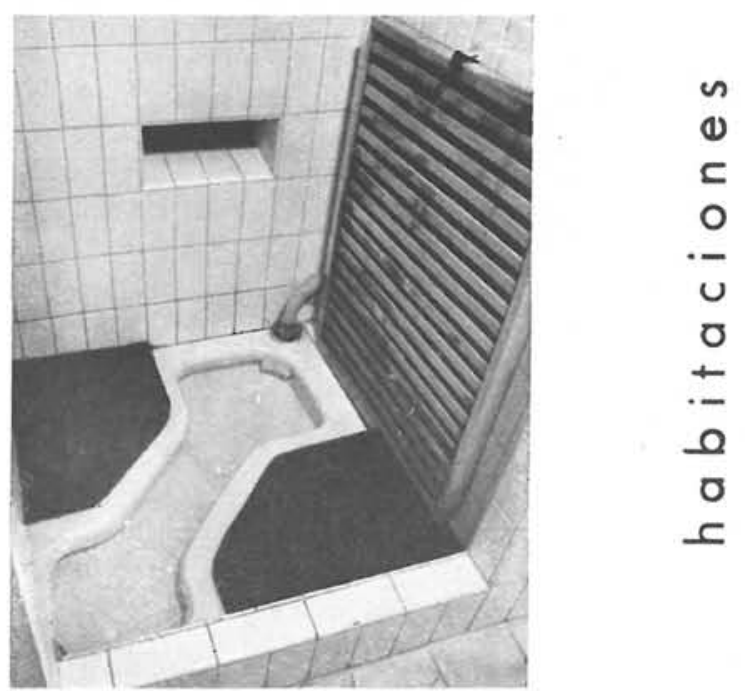




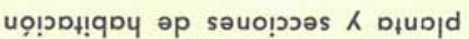
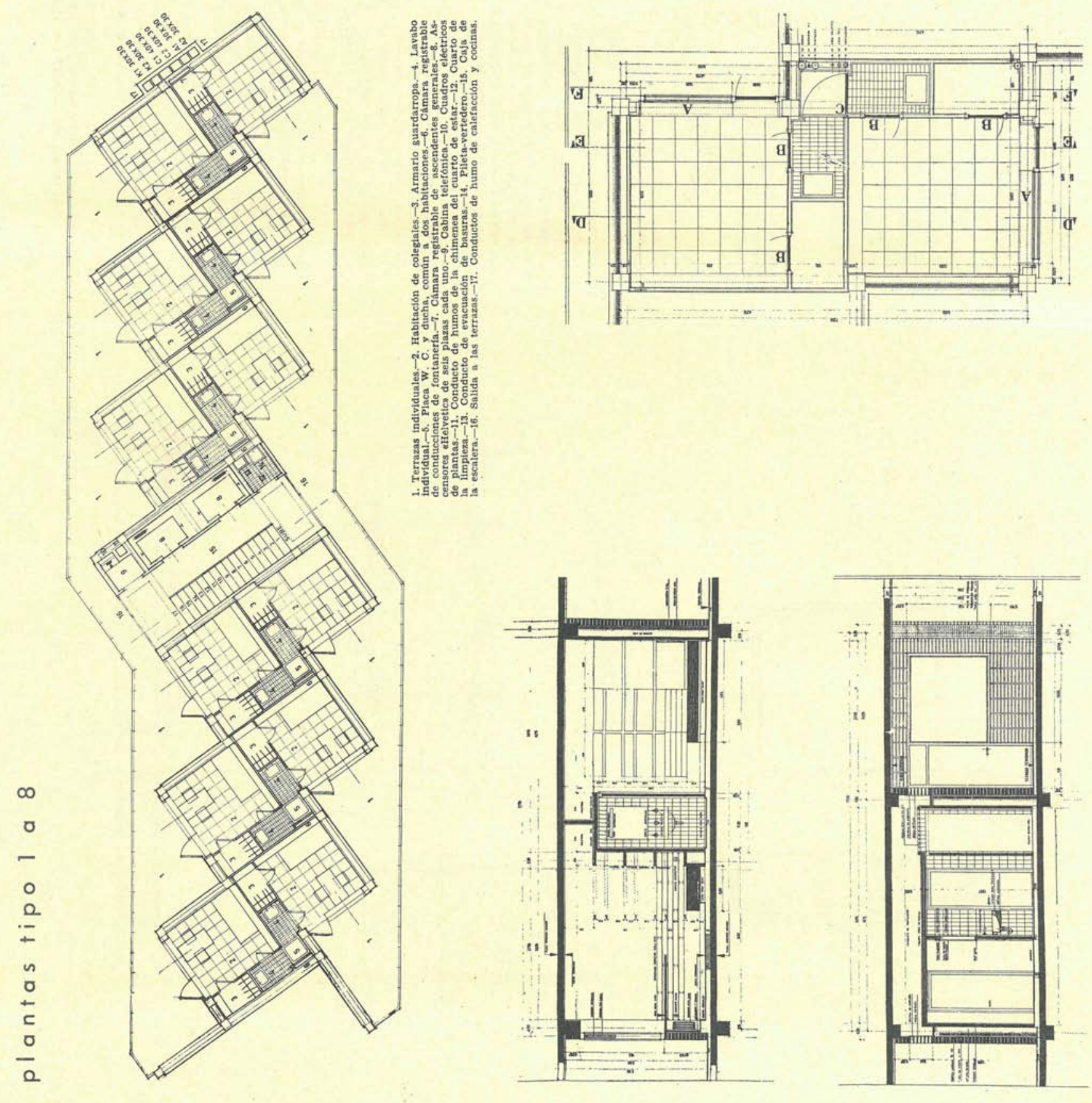


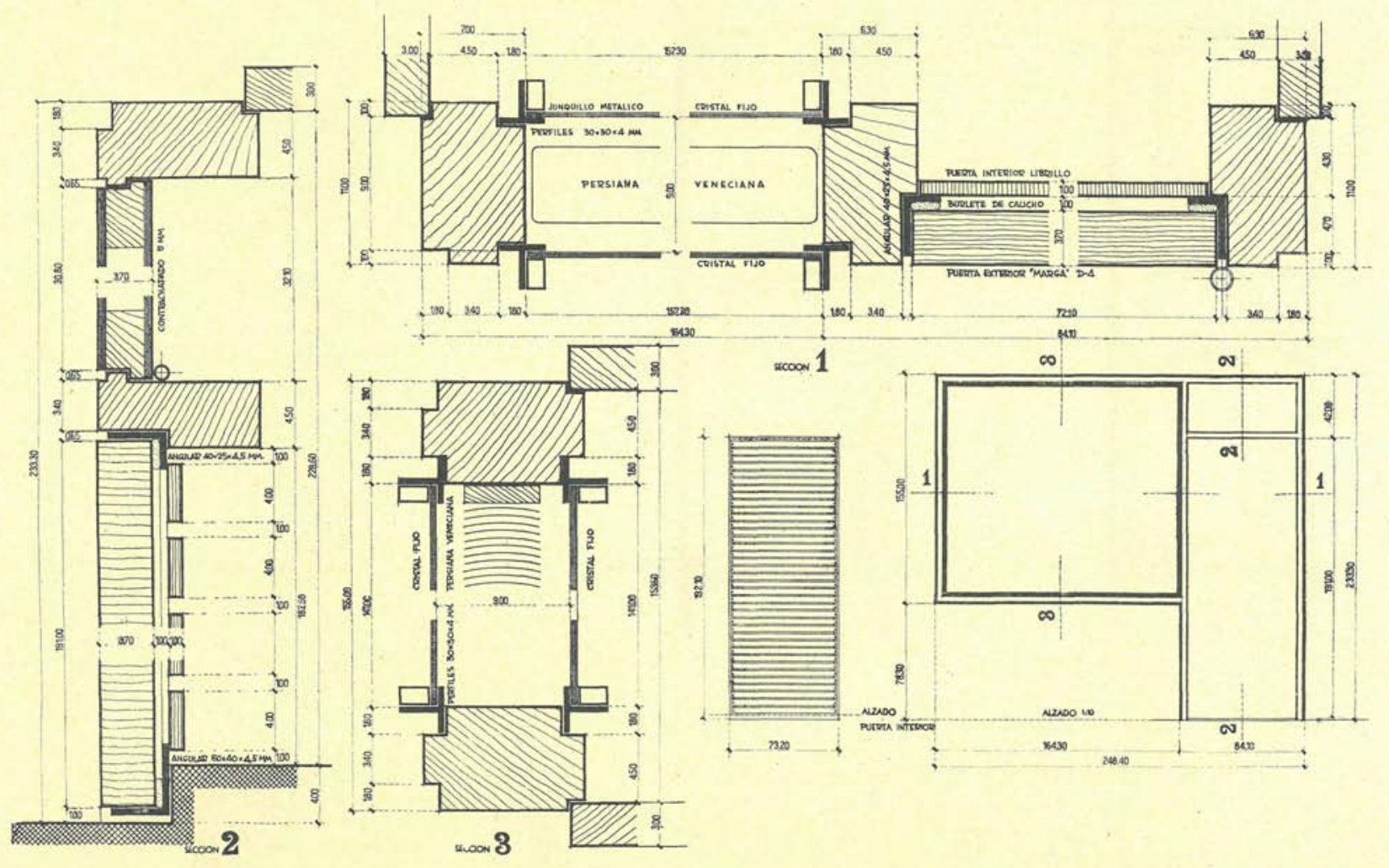

$D ! \perp \partial+u ! d \perp D \partial$

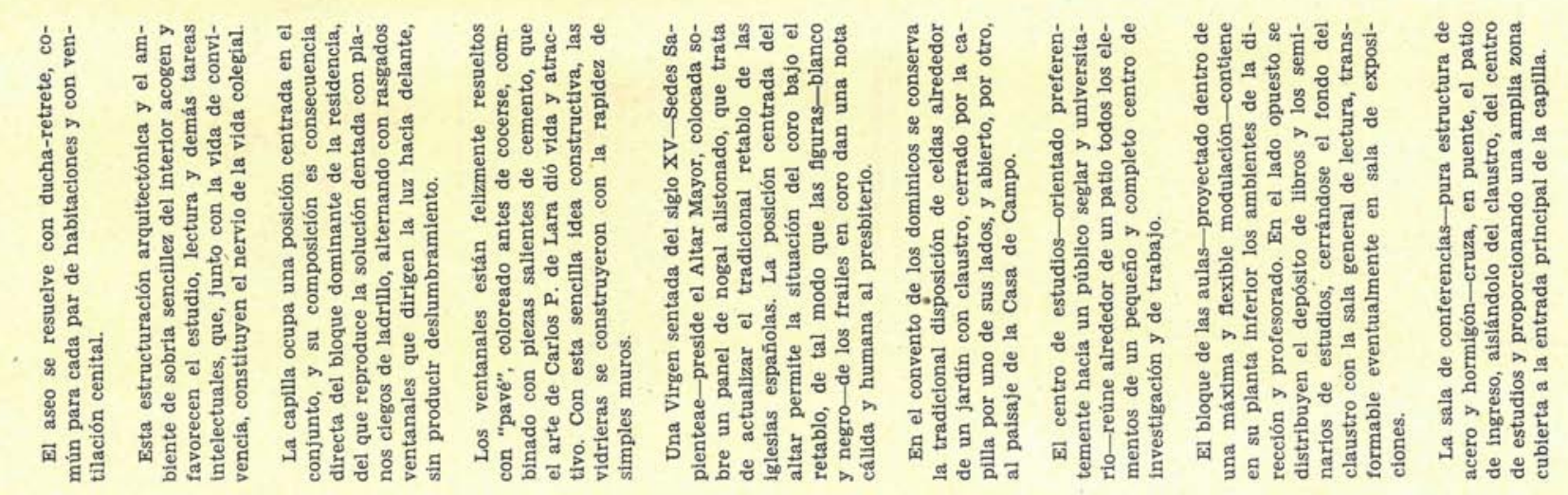

